\title{
Implementación de productos de apoyo de alta gama recomendados por el CENAREC en el proceso de la educación a distancia de la población asesorada en regiones educativas costarricenses
}

\author{
Implementation of high-end support products recommended by CENAREC \\ in the distance education process of the population advised in Costa Rican \\ educational regions
}

Implementação de produtos de suporte de ponta recomendados pelo CENAREC no processo de educação a distância da população atendida em regiões educacionais da Costa Rica

\author{
María de los Ángeles Calderón Jiménez \\ Centro Nacional de Recursos para la Educación Inclusiva \\ San José, Costa Rica \\ maria.calderon.jimenez@mep.go.cr \\ (D) ORCID: https://orcid.org/0000-0002-3111-0451 \\ Jorge Arturo Montero Segura \\ Centro Nacional de Recursos para la Educación Inclusiva \\ San José, Costa Rica \\ jorge.montero.segura@mep.go.cr \\ (1) ORCID: https://orcid.org/0000-0002-4229-8963
}

Recibido - Received - Recebido: 24 / 08 / 2021 Corregido - Revised - Revisado: 29 / 10 / 2021 Aceptado - Accepted - Aprovado: 12 / 11 / 2021

DOI: https://doi.org/10.22458/ie.v23i35.3934

URL: https://revistas.uned.ac.cr/index.php/innovaciones/article/view/3934

\begin{abstract}
Resumen: El Centro Nacional de Recursos para la Educación Inclusiva, dentro de sus funciones, brinda asesoría para que las personas estudiantes, en condición de discapacidad, puedan acceder a productos de apoyo tendientes a facilitar su proceso educativo. El propósito de la investigación, es analizar el uso que las personas docentes y estudiantes dan a dichos productos tecnológicos de alta gama, recomendados por los funcionarios, en el proceso de educación a distancia, durante la emergencia sanitaria experimentada en el curso lectivo 2020, por motivo del virus responsable de la Covid-19, esto en la población estudiantil en situación de discapacidad, asesorada en las regiones educativas costarricenses de Coto y Liberia. La investigación fue de tipo cualitativo, donde se trata de interpretar la realidad del acontecimiento que se investiga. Los informantes fueron 10 personas encargadas de familia de estudiantes en situación de discapacidad y 13 personas docentes. La información se recolectó a través de dos entrevistas, la información se procesó a través de unidades de análisis, de las cuales se desprenden categorías. Los resultados indican que los productos de apoyo de alta gama, en su mayoría, resultan útiles con la población asesorada, por lo que se concluye que su uso favorece la educación inclusiva.
\end{abstract}

Palabras clave: educación inclusiva, estudiantes, discapacidad, productos de apoyo, tecnología, educación a distancia.

Summary: The National Resource Center for Inclusive Education, within its functions, provides advice so that students with disabilities can access support products to facilitate their educational process. The purpose of the research is to analyze the use that teachers and students give to said high-end technological products, recommended by officials, in the distance education process, during the health emergency experienced in the 2020 school year, by reason for the virus responsible for Covid-19, this in the student population with disabilities, advised in the Costa Rican educational regions of Coto and Liberia. The research was of a qualitative type, where it is about interpreting the reality of the event under investigation. The informants were 10 people in charge of the families of students with disabilities and 13 teachers. The information was collected through two interviews, the information was processed through units of analysis, from which categories emerge. The results indicate that the high-end support products, for the most part, are useful with the counseled population, which is why it is concluded that their use favors inclusive education. 
Keywords: inclusive education, students, disability, assistive products, technology, distance education.

Resumen: O Centro Nacional de Recursos para Educação Inclusiva, dentro de suas funções, fornece conselhos para que os alunos com deficiência possam acessar produtos de suporte tendendo a facilitar seu processo educacional. O objetivo da pesquisa é analisar o uso que as pessoas professores e alunos fornecem produtos tecnológicos de ponta, recomendados por funcionários, no processo de educação a distância, durante a emergência sanitária vivenciada no ano letivo de 2020, devido ao vírus responsável pela Covid-19, esta na população estudantil com deficiência, aconselhou nas regiões educacionais da Costa Rica de Coto e Libéria. A pesquisa foi qualitativa, onde se trata de interpretar a realidade do evento sob investigação. Os informantes eram 10 pessoas gestores familiares de alunos com deficiência e 13 professores. A informação é coletadas por meio de duas entrevistas, as informações foram processadas por meio de unidades de análise, das quais eles dão categorias. Os resultados indicam que os produtos assistivos de alta qualidade, em sua maioria, são útil com a população aconselhada, portanto, conclui-se que sua utilização favorece a educação inclusiva.

Palabras clave: educação inclusiva, alunos, deficiência, produtos assistivos, tecnologia, educação para distância.

\section{INTRODUCCIÓN}

El contexto de aula es el espacio donde estudiantes y docentes exponen ideas, socializan, discuten, construyen y reconstruyen, tanto conocimientos como valores. Es en este lugar, donde se debe promover la participación de todo el estudiantado, de manera que se tomen en cuenta sus capacidades, habilidades, intereses, formas de aprender, estilos y ritmos de aprendizaje, para así, generar el respeto por el otro y el reconocimiento de su diversidad, ya que, como explica Arnaiz (2003) "A menudo encontramos que la diversidad es entendida como un problema, más que como una maravillosa oportunidad de aprender sobre la variedad de vida de otras personas y también, sobre lo que significa ser humano: ser incluido, valorado y respetado por quien uno es, en un mundo diverso y plural por naturaleza" (p. 1).

Besalú (2002) afirma que: "Sin una educación en la diversidad y para la convivencia, fundada en los derechos humanos, la educación no tiene futuro en esta sociedad compleja y planetaria" (p. 39); de ahí la importancia de la educación inclusiva, donde todo el alumnado tiene la oportunidad de acceder a una educación que responda a sus necesidades.

Por lo tanto, esta temática debe ser de gran interés en el área de las Ciencias de la Educación, por cuanto desde la entrada en vigencia de la ley 7600 , en el año 1996, se dio un gran avance en los derechos de las personas con discapacidad, siendo uno de ellos el acceder al sistema educativo en equidad de condiciones. Para hacerlo efectivo, estudiantes con alguna condición, requieren de diferentes tipos de apoyos, los cuales pueden ser personales, materiales, tecnológicos, organizativos y curriculares (Ministerio de Educación Pública, 2013). Este estudio se enfoca en los productos de apoyo de alta tecnología, también llamados de alta gama, los cuales son un importante insumo para que las personas estudiantes en condición de discapacidad, puedan hacer efectivo su derecho a la educación.

Con respecto al tema de productos de apoyo, se conoce de la investigación de Aguilar et al. (2009), donde investigan qué clase de productos técnicos de apoyo deben ser diseñados para favorecer la inclusión social de personas en situación de discapacidad; encuentran que los de movilidad laboral son los más necesarios.

Otro de los estudios indagados fue el publicado por Jiménez (2016), cuyo propósito apunta a determinar el impacto psicosocial de los productos de apoyo más utilizados por las personas con discapacidad auditiva; el resultado determina la necesidad de usar los de amplificación de sonido.Por su parte Rojas, Abello, Garrido \& Simanca (2019), comentan que se hizo una investigación que crea un software, donde la voz del profesor se traduce en texto escrito, que llega al dispositivo inteligente o a una computadora de los estudiantes que lo requieran. 
Otra investigación sobre el uso de dispositivos de apoyo para facilitar las funciones de personas con algún tipo de discapacidad, es la de González-Hernández et al. (2019), donde logran diseñar y construir un dispositivo mecatrónico para terapia ocupacional en infantes, el cual capta su interés y entusiasmo, motivando al menor a realizar los ejercicios. Víquez-Alfaro et al. (2019) determinan la necesidad de emplear mayor tecnología, que posibilite que las personas con discapacidad accedan a la información en equidad, favoreciendo al estudiantado que utilice dichos apoyos. Ríos (2017), estudia la accesibilidad de las Tecnologías de la Información y la Comunicación (TICs) en Costa Rica, y menciona que es imprescindible fortalecer y reconocerlas desde la accesibilidad universal, de forma tal que se exijan políticas y normas en las organizaciones para que sean accesibles.

Los resultados y conclusiones de las investigaciones presentadas, evidencian la importancia de fortalecer la inclusión de las personas en situación de discapacidad, tanto en los procesos educativos, como a nivel social y cotidiano, lo cual se puede hacer efectivo, entre otras cosas, a través de un producto de apoyo.

En Costa Rica, la educación inclusiva responde a un proceso histórico que hace posible y efectivo el derecho a la educación de todas las personas, es así como en 1990, hay referencia a la Conferencia Mundial sobre Educación para Todos, realizada en Tailandia por la Organización de las Naciones Unidas para la Educación, la Ciencia y la Cultura (Unesco); también está la Declaración de Salamanca sobre Necesidades Educativas Especiales, que se aprueba en el año 1994, la cual reafirma el derecho a la educación y el deber de las escuelas de acoger a la niñez, independientemente de sus condiciones físicas, intelectuales, sociales, emocionales, lingüísticas u otras.

Específicamente, en el contexto nacional, se da la creación de la ley 7600 en el año 1996, Ley de Igualdad de Oportunidades para las Personas con Discapacidad, la cual nace con el objetivo de brindar a dicha población, los derechos en los ámbitos educativo, social, laboral, recreativo, entre otros. En el año 1998 se aprueba el Código de la Niñez y la Adolescencia, con el fin de reafirmar la obligación de respetar los derechos de esta población, destacando la participación y opinión respecto a la calidad de educación que reciben.

Por otra parte, en el 2008 se promulga la Convención Internacional de derechos de las personas con discapacidad, también está la ley 9379 de Promoción de la Autonomía Personal de las Personas con Discapacidad del año 2016 y en ese mismo año, el Reglamento a la ley 9303 Ley de creación del Consejo Nacional de Personas con Discapacidad (Conapdis), donde se establecen las disposiciones normativas para garantizar que los diversos sectores de la sociedad cumplan con los derechos humanos de la población con discapacidad. En el año 2018, las Naciones Unidas aprueban la Agenda 2030, en la que se establece garantizar una educación inclusiva, equitativa y de calidad.

Además, está el Decreto Ejecutivo n. 40955 del año 2018, emitido por el Ministerio de Educación Pública, denominado Establecimiento de la inclusión y la accesibilidad en el sistema educativo costarricense; en el 2019 se da la Directriz n. ${ }^{\circ}$ 051-MTSS-MICITT sobre sitios Web accesibles y finalmente, en el año 2020 se aprueba la ley 9822, la cual establece el "Reconocimiento y Promoción de la Lengua de Señas costarricense, como patrimonio cultural y lingüístico de la comunidad de personas sordas".

Como se muestra, en Costa Rica existe un avance jurídico importante, en lo que respecta al reconocimiento de los derechos de las personas con discapacidad, lo que incide directamente en la educación. Es así como desde el Centro Nacional de Recursos para la Educación Inclusiva (CENAREC), institución de mínima desconcentración del Ministerio de Educación Pública, se promueve esa inclusión, de forma tal que las personas estudiantes puedan estar en el sistema educativo, con los apoyos necesarios por su condición. La familia o el centro educativo, contacta al Departamento de ayudas técnicas (Daat), perteneciente al CENAREC, para solicitar la asesoría respecto a los productos de apoyo que requiere la persona estudiante; se les indica que deben presentar una boleta que está en la página Web, la cual debe ir sellada y con el visto bueno de la Dirección del centro educativo, a la vez, adjuntar un informe 
pedagógico y dictamen médico que refleje la condición de discapacidad. Los requisitos son revisados y analizados por los profesionales del departamento, para posteriormente, coordinar una fecha de encuentro, ya sea visita al centro educativo o atención virtual. En el momento de la asesoría, se hace la entrevista a la familia, al estudiante y a representantes del centro educativo, además se analizan en conjunto, cuáles son los productos de apoyo más pertinentes.

Para efectos de este estudio, se hace referencia a los apoyos materiales o tecnológicos recomendados por el Daat, entre los años 2017 y 2019, específicamente, los de alta gama, que son aquellos que tienen un elevado costo y cuentan con la última tecnología.

Con respecto a los productos de apoyo educativo de alta gama, según la búsqueda realizada en diferentes fuentes, no se encontró de forma específica el término, por este motivo es que se realiza una indagación de forma separada, para luego crear el propio concepto. Los productos de apoyo son el elemento o elementos que requiere una persona con discapacidad, que contribuye a mejorar su funcionalidad y autonomía personal, específicamente, respecto al producto de apoyo educativo; para el Ministerio de Educación Pública (2013), son "recursos, actividades y estrategias tendientes a facilitar el proceso de aprendizaje de las y los estudiantes (...), con el fin de responder a la diversidad y minimizar las barreras para el aprendizaje y la participación que experimentan estos, en función de los fines y objetivos establecidos en la educación".

Por otra parte, Schirmer (2020) dice que "alta gama", se relaciona directamente con alta tecnología y que su uso se incrementa en los últimos años, donde el acceso a la portabilidad de las tecnologías móviles incide de forma directa, ejemplo de ello es el uso de teléfonos celulares y tabletas con pantallas táctil.

Con los conceptos anteriores, para esta investigación, los productos de apoyo de alta gama se definen como aquellos dispositivos de alta tecnología que le permiten a la persona estudiante acceder al currículum, facilitando su proceso educativo, en un sistema que responde a la diversidad y a la inclusión.

Algunos de los dispositivos tecnológicos que se pueden nombrar y que apoyan al estudiantado que presenta situación de discapacidad, son la computadora portátil, la tablet, teléfono celular inteligente y el dispositivo de control ocular o táctil para la comunicación.

Por otra parte, debido a la emergencia sanitaria que inició en marzo del 2020, por causa del virus responsable de la COVID-19, Costa Rica realiza acciones y ajustes entre los que se destaca la suspensión presencial de las lecciones en todas las instituciones educativas del país; por este motivo, el Ministerio de Educación Pública (MEP) adapta la oferta educativa a las condiciones del momento, donde los docentes trabajan a distancia con sus estudiantes a través de diferentes medios, entre los que se citan los tecnológicos.

A partir de la revisión documental realizada, en lo que respecta a discapacidad, Hernández (2015) indica que es el resultado de la interacción entre una persona con deficiencia física, mental y sensorial, que limita la capacidad de ejercer una o más de las actividades esenciales de la vida diaria, y un entorno con barreras que no le ofrece los servicios y apoyos requeridos, limitando y restringiendo su participación.

Con el anterior contexto, y en una época que se caracteriza por el uso de las tecnologías y productos de apoyo para garantizar la educación inclusiva, es que surge este estudio, para valorar la implementación oportuna de dichos dispositivos en el proceso educativo a distancia, que surge por el virus responsable de la COVID-19, acontecida durante el año 2020.

La investigación se llevó a cabo en las regiones educativas costarricenses de Coto, que comprende a los cantones de Pérez Zeledón, Grande de Térraba y Coto, y los de la Región Educativa de Liberia que agrupa Cañas, Santa Cruz, Nicoya y Liberia, de donde surge el problema de estudio: ¿Cómo se han implementado los productos de apoyo de alta gama recomendados por el CENAREC en el proceso 
educativo en la educación a distancia, de la población estudiantil en situación de discapacidad asesorada en las regiones de Coto y Liberia?

A partir del planteamiento del problema, se proponen como objetivo general analizar el uso que las personas docentes dan a los productos de apoyo de alta gama, recomendados por el CENAREC en el proceso de educación a distancia, de la población estudiantil en situación de discapacidad, asesorada en las regiones de Coto y de Liberia, durante la emergencia sanitaria causada por el virus responsable de la COVID-19, experimentada en el curso lectivo 2020; además interesó investigar de manera específica el concepto de discapacidad y productos de apoyo que tienen las personas docentes, y padres/madres de familia de estudiantes en condición de discapacidad; así como el análisis de las opiniones de las personas docentes y padres y madres de familia, respecto al uso del producto de apoyo de alta gama, en el proceso de educación a distancia, por último, la valoración de la utilidad del producto de apoyo utilizado por el estudiantado en situación de discapacidad, con respecto a la educación a distancia que han recibido, durante la emergencia sanitaria causada por el virus responsable de la COVID-19.

\section{MATERIALES Y MÉTODOS}

Este estudio se enmarca dentro del enfoque cualitativo, en el que se trata de interpretar la realidad del acontecimiento que se investiga, de forma tal que "la preocupación directa del investigador se concentra en las vivencias de los participantes, tal como fueron (o son) sentidas y experimentadas" (Hernández, Fernández y Baptista, 2014, p. 8.).

El propósito es conocer la experiencia de los sujetos de estudio, la forma en que perciben el fenómeno educativo; en este caso, profundizando en sus puntos de vista sobre los productos de apoyo tecnológico de alta gama, que utiliza el estudiantado.

Las personas participantes son 10 personas encargadas de familia, de estudiantes en situación de discapacidad, cinco pertenecientes a la región educativa de Coto y cinco a la de Liberia, tanto del nivel de primaria como de secundaria, los cuales adquieren un producto de apoyo de alta gama, como recomendación de la asesoría que realiza el Daat, entre los años 2017 y 2019. Las condiciones de discapacidad que presentan las personas estudiantes varían: discapacidad visual, trastorno del espectro del autismo (TEA), espina bífida, artrogriposis y parálisis cerebral. Participan también 13 personas docentes de educación primaria y secundaria que tienen a cargo a las personas estudiantes, tanto docentes de grado, del equipo de apoyo y de secundaria, según sea el nivel.

Para la selección de los participantes, se consulta al Daat, perteneciente al CENAREC, específicamente, a las personas encargadas que trabajan en las regiones educativas de Coto y Liberia. Se les solicita la recomendación de cinco estudiantes de cada una de las zonas, el criterio de selección es que se les haya brindado asesoría entre los años 2017 y 2019, que cuenten con el producto de apoyo tecnológico de alta gama y que estén dentro del sistema educativo al momento de la investigación.

Posterior a este proceso de indagación, se procede a leer los expedientes de las personas estudiantes, a fin de obtener datos para su ubicación, se realiza un primer contacto con los encargados y las personas docentes para comentarles el objetivo de la investigación, así como la solicitud de colaboración para participar, mediante una entrevista que se hace posteriormente.

Debido a la emergencia sanitaria provocada por el virus responsable de la COVID-19, las entrevistas se realizan con herramientas como: llamada telefónica, llamada por WhatsApp ${ }^{\oplus}$ y mediante la plataforma MS Teams. 
Para llevar a cabo la recolección de datos, se utilizan dos entrevistas semiestructuradas que se elaboran de forma tal que al aplicarse, se desarrolle una conversación, como lo plantean Taylor y Bogdan (2006), la guía de entrevista obtiene y a la vez clarifica, lo que la persona informante quiere decir, se elabora con preguntas que permiten hacer un sondeo de los detalles de sus experiencias y los significados que le atribuyen al fenómeno en estudio. Esta guía es examinada por expertos, que según Cooke y Goznes (2008), citados por Morales y Cooke (2008), evalúan su contenido; posteriormente, el equipo investigador analiza sus opiniones para finalmente, tomar las decisiones respecto a la herramienta de recolección de información.

En ambas entrevistas aplicadas, tanto a los padres/madres como a las personas docentes, se les solicita datos generales para contextualizar a la persona estudiante, luego se indaga sobre los productos de apoyo recibidos mediante la asesoría del Daat, posteriormente, preguntas relacionadas con los objetivos específicos de la investigación, haciendo diferencias al ser docentes, respecto al uso del producto de apoyo en la persona estudiante y en el caso de los padres y madres, al observar y vivenciar el desenvolvimiento de su hijo o hija como usuario del producto de apoyo tecnológico en el proceso educativo a distancia.

La entrevista cuenta con 10 preguntas, entre las cuales se destaca la situación de discapacidad que presenta la persona estudiante, el producto de apoyo con que cuenta; además, qué significado le dan a la palabra discapacidad y a productos de apoyo, por otra parte, si consideran que ha sido de utilidad en la educación a distancia y en qué forma lo utilizan, limitaciones que presenta y formas para mejorar su uso, si existe acompañamiento y seguimiento. Las personas docentes tienen una pregunta adicional relacionada con la forma en que lo han utilizado en la mediación pedagógica, en la educación distancia.

Con respecto a los criterios de confiabilidad y validez, "la confiabilidad cualitativa se denomina dependencia, la consistencia lógica... que equivale más bien al concepto de estabilidad" (Hernández, Fernández y Baptista, 2008, p. 662); a la vez, se siguen los planteamientos e instrucciones de verificación de validez y confiabilidad de los estudios cualitativos de los mismos autores. De esta manera, los criterios para la selección de los participantes, de forma que sean convenientes y vinculados metodológicamente al estudio, por lo que se procede a recoger los datos y analizarlos a partir de los pasos y procedimientos establecidos.

Posterior a la recolección de la información, se organiza en tablas, para documentar de manera objetiva las respuestas, describiéndola lo más veraz posible. A la vez, se toma en cuenta "la amenaza a la confiabilidad cualitativa o "dependencia" [que] puede ser, básicamente: los sesgos que puede introducir el investigador, en la sistematización durante la tarea en el campo y el análisis" (Hernández, Fernández y Batista, 2008, p. 662).

La validez del estudio se evidencia, al percibir el significado de los datos y relacionarlos con el planteamiento del problema, teniendo la apertura de escuchar a los participantes para lograr una interpretación lo más ajustada a la realidad, según los objetivos planteados en la investigación.

Para efectos de este estudio, el análisis de la información se llevó a cabo, de acuerdo con los criterios más relevantes obtenidos en las unidades de análisis, que para Buendía, Colás y Hernández (2004), "[...] no es una etapa precisa o temporalmente determinada en una fase concreta de la investigación [...] opera por ciclos, tiene lugar a lo largo de todo el proceso de investigación, es concurrente a la recogida de datos y trabaja con los datos de forma exhaustiva" (p. 289); de las unidades de análisis se obtuvieron categorías, según las respuestas dadas. 


\section{DISCUSIÓN DE RESULTADOS}

Luego de la recolección de datos y el análisis de los mismos, uno de los principales hallazgos es que los productos de apoyo tecnológicos de alta gama, recomendados por el CENAREC al estudiantado en condición de discapacidad, cumplen el objetivo de colaborar con que el proceso educativo a distancia sea accesible, logrando la equidad en las oportunidades, tal y como se establece en los diferentes instrumentos jurídicos analizados.

A partir de las respuestas emitidas por las personas participantes, surgen dos unidades de análisis denominadas Discapacidad y productos de apoyo y Proceso educativo a distancia. De estas, a la vez se desprenden diferentes categorías con sus datos más relevantes.

FIGURA 1

Unidad de análisis 1.

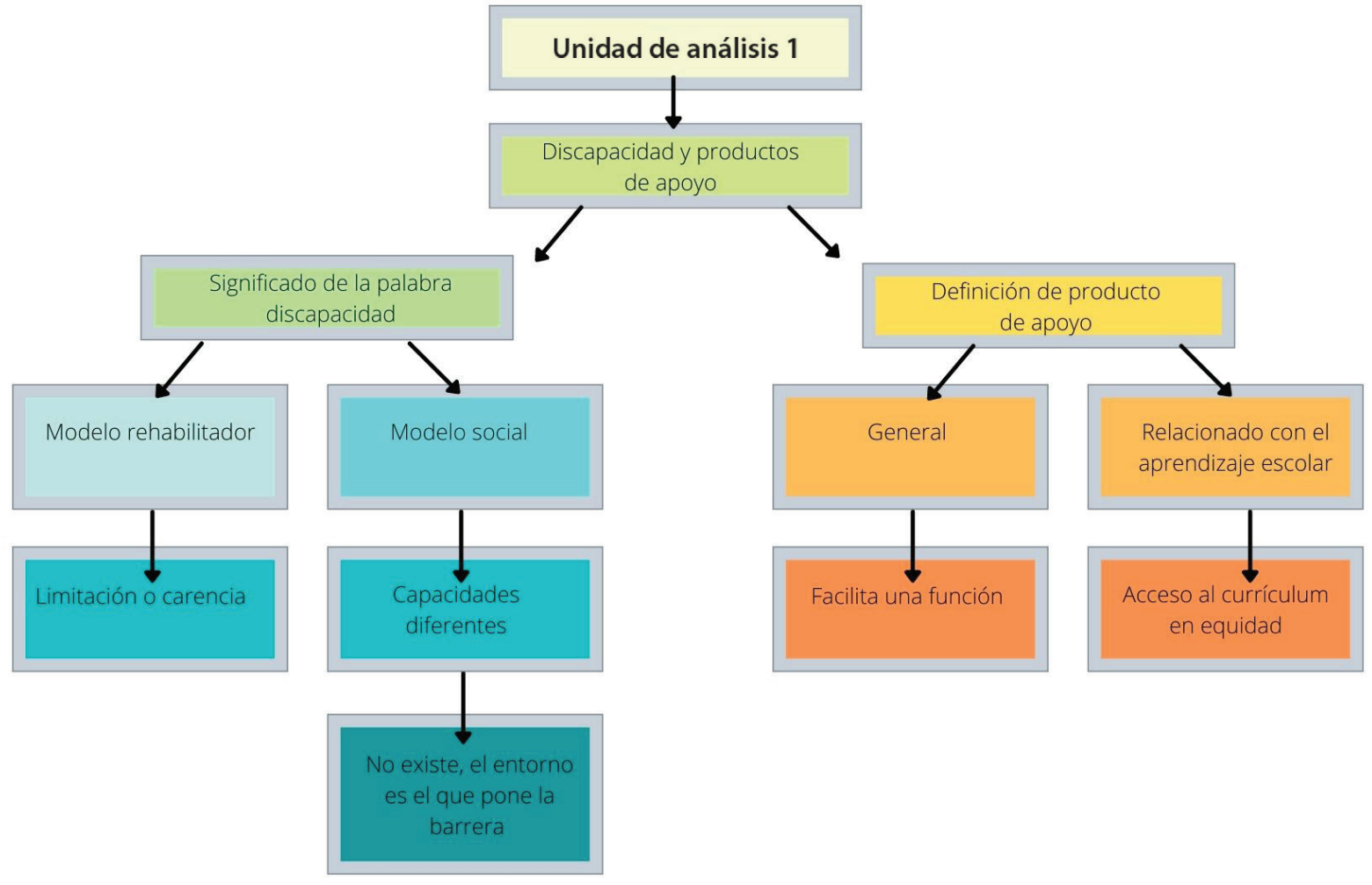

Fuente: Elaboración propia.

Esta primera unidad de análisis se refiere, a lo que para las personas participantes significan los conceptos de discapacidad y productos de apoyo, información de suma relevancia para conocer cuál es el concepto que tienen, lo que influye directamente en el tipo de educación impartida y recibida por los estudiantes, a la vez que puede determinar las oportunidades de acceso al sistema educativo. De las respuestas brindadas surgen las siguientes categorías:

Significado de la palabra discapacidad: La mayoría de los participantes concibe la discapacidad como una limitación o una carencia, lo que se evidencia en expresiones como: "No tener la capacidad de hacer algo", "una persona que se ve limitada a hacer algunas funciones", "discapacidad es limitación", "falta de alguna capacidad para hacer un trabajo, para estudiar". Otras personas docentes y la mayoría de los 
padres/madres, la perciben desde el modelo rehabilitador, como lo dice Palacios, A. (2008) "el énfasis se sitúa en la persona y su 'deficiencia', caracterizada como una anomalía patológica que impide a la persona realizar actividades que se consideran 'normales'" (p. 61). Es decir, sus hijos, hijas o estudiantes presentan una limitación para ejercer alguna función específica; esta concepción limita el acceso en equidad de oportunidades, por cuanto se concibe que al tener una deficiencia, no podrán acceder a todas las actividades o recursos al igual que sus compañeros o compañeras, lo que conlleva una visión que limita posibilidades, sin poder hacer pleno uso de sus derechos fundamentales. Otros, en su mayoría las personas docentes, lo ven desde el modelo social, el de tener capacidades diferentes, ejemplo de ello, son las siguientes respuestas: "logran hacerlo diferente, de otra forma", "no hay discapacidades, hay condiciones", "hay capacidad de hacer las cosas, pero con apoyo". También mencionan que la discapacidad no existe, lo que hay son obstáculos en el contexto, lo cual se nota en respuestas como "condición que no depende de las personas, sino de las barreras del entorno". En la actualidad se busca que prevalezca el enfoque social de la discapacidad, que considera que las causas que la originan son sociales (Victoria, 2013), es decir, la discapacidad como tal, es el resultado de la interacción entre una persona que experimenta algún grado de limitación funcional y el contexto que no le ofrece apoyos oportunos y efectivos que lo harían accesible (Hernández, 2015), con la consecuencia que la persona se vea limitada en la realización de sus actividades y restringida en su participación. Esta perspectiva social es enriquecedora dentro del sistema educativo, por cuanto afirma que todas las personas, sin importar sus características, pueden hacer uso de sus derechos, vivir en armonía y equidad al tener las mismas oportunidades.

Definición de productos de apoyo: En esta categoría, las respuestas van en dos vías: a nivel general, como el recurso que facilita una función y de forma más específica, relacionado con el aprendizaje escolar. Expresiones que ejemplifican a nivel general lo que es un producto de apoyo son: "puede ser desde una silla de ruedas, hasta una computadora, que facilita hacer algo", "un recurso, un medio para ayudarle a la persona", "aplicaciones para que lo que haga ella sea más fácil". Para Carrascosa (2015), los productos de apoyo son aquellos como dispositivos, aparatos o adaptaciones que tienen la función de suplir o complementar las limitaciones funcionales de las personas con discapacidad. Con las respuestas anteriores, se evidencia que para las personas participantes, los recursos de apoyo son necesarios para que el estudiantado pueda ver facilitadas sus acciones cotidianas. Respecto al producto de apoyo, visto desde el aprendizaje, dicen que es un "instrumento que va a apoyar o acompañar el desarrollo de estudiantes para la evolución del aprendizaje", "ayuda a sus avances del estudio", "algo que va a facilitar al estudiante tener una mejor calidad de enseñanza"; es decir, aquí están haciendo referencia a los productos de apoyo educativo, los cuales se emplean para hacer accesibles las clases, de forma tal que les permita la equidad de condiciones respecto a los demás estudiantes que no presentan una condición de discapacidad, lo que lleva a facilitar su proceso de educativo, respondiendo a la diversidad y minimizando las barreras para el aprendizaje, (MEP, 2013), lo que trae grandes beneficios para los estudiantes, haciendo efectivo su derecho a la educación. (Ver Figura 1)

Como ya se ha mencionado, por motivo de la emergencia sanitaria acontecida por el virus responsable de la COVID-19, la modalidad educativa en el 2020 fue a distancia. En la unidad de análisis 2, se hace referencia al uso del producto de apoyo tecnológico de alta gama recomendado por el CENAREC, mediante las asesorías brindadas por el Daat, a solicitud de las familias o la institución educativa. De aquí, se extrajeron las siguientes categorías:

Uso del producto de apoyo: Esta categoría refiere la opinión que tienen los padres/madres de familia y las personas docentes, respecto al uso, propiamente dicho, que le dieron las personas estudiantes al producto de apoyo tecnológico de alta gama, en la educación a distancia durante el año 2020. En el caso de las personas estudiantes que el CENAREC les recomendó computadoras portátiles, tabletas o teléfonos celulares inteligentes, las opiniones demuestran que en la educación a distancia, favorece en que puedan realizar las tareas escolares y recibir las clases, dado que es un recurso tecnológico 
que permite la virtualidad. Algunas de las respuestas emitidas por las personas informantes fueron: "a diario, clases de lunes a viernes a la 1 pm., clases por MS Teams" ", "ahí hace sus tareas", "ha colaborado mucho porque gracias a la Tablet actualmente recibe las clases". Es decir, padres, madres y docentes concuerdan en que le dan un gran uso, por cuanto estos dispositivos le permiten al estudiantado acceder al sistema educativo. Por otra parte, a los que presentan dificultades en su movilidad, unidos a trastornos de lenguaje, se les recomendó el uso del dispositivo de control ocular donde, con la mirada pueden activar sonidos o su voz, y de esa manera hablar o escribir (Tavid, 2018), o también mediante el tacto, con lo que ganan autonomía, interacción social y desenvolvimiento personal. Las personas estudiantes que cuentan con el dispositivo; en algunos casos, logran comunicarse por primera vez o de manera más fluida, lo que se ejemplifica en respuestas como: "ha permitido el desarrollo del lenguaje y la comunicación del niño, ahora es más fácil la comunicación”, "mucho apoyo en cuanto a la comunicación, muy bueno". Lo anterior, evidencia un gran avance para la persona estudiante, ya que la comunicación, de cualquier forma que se haga, es básica para relacionarse, les permite interactuar y con ello, tener la oportunidad de enriquecer su aprendizaje. No obstante, en dos situaciones específicas, no se usa el dispositivo de la mejor forma, aquí las respuestas fueron: "La docente como tal no lo usa, desconoce su funcionamiento", "ella le interesaría utilizarlo bien si pudiera" (refiriéndose a la estudiante). La situación que se narra es que el proceso de adquisición del producto se dio con una docente, pero al cambiar el estudiante de nivel, la profesora actual desconoce su funcionamiento y la familia a nivel muy básico, por lo que opinan que no se le está dando la utilidad óptima, limitando el objetivo para el cual fue obtenido. En el otro caso, ningún docente le ha explicado bien a la familia su uso.

Satisfacción con el producto de apoyo: En esta categoría, las personas participantes expresan su opinión con respecto a la satisfacción sobre el uso y rendimiento del producto de apoyo, es así como se expresan positivamente: "es muy importante, le puede servir a muchos niños más apoyos de este tipo", "ha sido de gran ayuda", "le ha ayudado mucho". Existe conocimiento de las personas docentes y de padres y madres, sobre las posibilidades que brindan los productos de apoyo para la población estudiantil en condición de discapacidad, "se logran aprender nuevas formas de desempeño en las actividades cotidianas" (Palacios, 2013, p. 94). A su vez, algunos participantes destacan en que se debe optimizar su uso: "puede potenciarse más", "le cuesta un poquito manejarla", "tiene la tecnología pero una limitación es el internet". Estas respuestas evidencian que el dispositivo tecnológico de alta gama es un buen recurso, pero puede mejorar el conocer más sobre sus posibilidades, incluso el acceso efectivo al internet es básico, por cuanto si tienen el dispositivo y no tienen conexión a una red, su uso puede verse disminuido. Por otra parte, algunos expresan que necesitan mayor acompañamiento y seguimiento para su uso, lo cual se nota en respuestas como: "ojalá hubiera la posibilidad de ir a donde esté la terapeuta ocupacional y ahí mismo actualizar la Tablet, poder ponerle nuevos y más programas, que exista siempre ese canal de comunicación", "necesitamos seguimiento", "necesitamos capacitación en el uso del producto de apoyo". Otras respuestas como "ocupamos que sea más rápido el proceso, fue muy lerdo", "acortar el proceso, ahora es más complicado, tarda más, el proceso debería ser más ágil"; evidencian que el trámite es lento y tardan en recibir el producto de apoyo, lo que hace que mientras lo obtienen, las personas estudiantes se vean limitados a accesar al currículo en igualdad de condiciones y sus docentes, a la vez, tengan restringido el proceso educativo con este. No obstante, se aclara que el CENAREC, específicamente el Daat, lo que da es asesoría en el recurso de apoyo que necesita el estudiante en condición de discapacidad. Girar los recursos económicos para la adquisición del mismo, va a depender de otras entidades del Ministerio de Educación, como lo es la Dirección de Programas de Equidad y el Departamento de Apoyos Educativos para el Estudiantado con Discapacidad

Mediación pedagógica: “Entendemos por mediación pedagógica el tratamiento de contenidos y de las formas de expresión de los diferentes temas, a fin de hacer posible el acto educativo, dentro del horizonte de una educación concebida como participación, creatividad, expresividad y relacionalidad" (Gutiérrez y Prieto, 1993, p. 2). En el caso de nuestro país, se enmarca dentro de un proceso de transformación 
curricular que se está desarrollando en el sistema educativo, el cual "implica la implementación de enfoques educativos integradores e inclusivos, con el aprovechamiento de las tecnologías digitales, que propulsen la accesibilidad y la incorporación de todas las personas participantes" (MEP, 2021). La misma responde a un diseño curricular a partir de la adquisición de habilidades en diferentes condiciones, ambientes y situaciones. Es así como el equipo investigador establece a la mediación pedagógica, como una de las categorías que se desprende de la segunda unidad de análisis, por cuanto todos los esfuerzos para que el estudiante en condición de discapacidad, acceda a la educación, se enfrenta de manera directa con la mediación que se lleve a cabo en las aulas. Para Gutiérrez y Prieto (1993), la mediación pedagógica se organiza en tres fases, relacionadas con el tratamiento desde el tema, desde el aprendizaje y desde la forma. El tratamiento desde el tema, se relaciona con los recursos pedagógicos destinados a hacer la información accesible a la persona estudiante, en el caso de esta investigación, se relaciona con los productos de apoyo tecnológico o de alta gama.

FIGURA 2

Unidad de análisis 2.

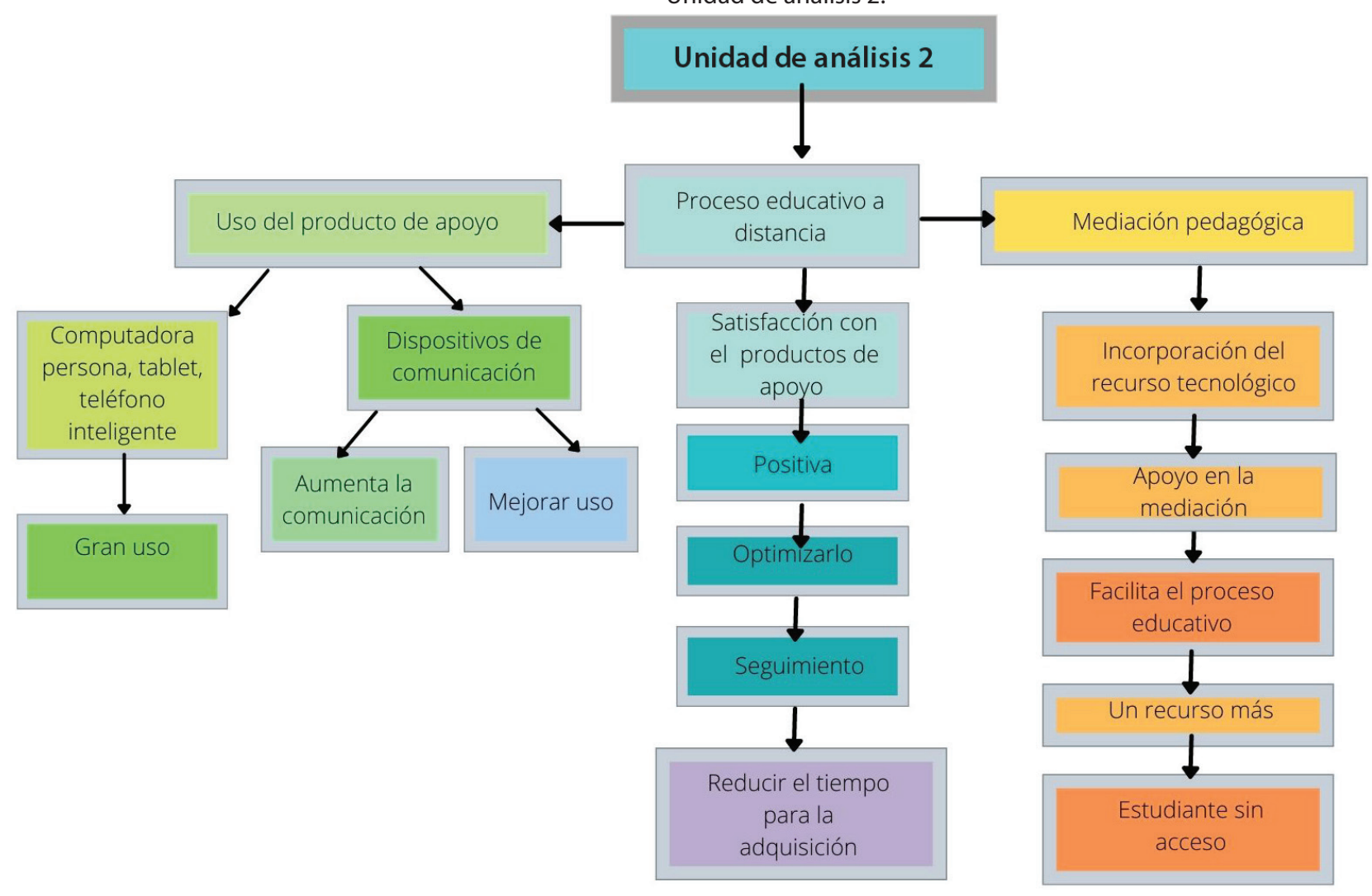

Fuente: Elaboración propia.

De esta forma y respondiendo a las demandas actuales, es que las personas docentes han venido incorporando herramientas tecnológicas en el desarrollo de sus clases, lo cual se maximiza al pasar a la modalidad a distancia en el año 2020, por motivo del virus responsable de la COVID-19.

Las personas estudiantes que cuentan con el dispositivo tecnológico de alta gama, han visto enriquecido su proceso educativo, por cuanto lo incorporan a las clases teniendo la posibilidad de usarlos, lo cual es evidente en respuestas como: "los profesores le permiten sacar fotos de lo que están escribiendo", "por gustarle mucho la tecnología ha investigado y aprendido por su propia cuenta, mucho más cosas que las 
que se le dan en el colegio", "La niña tenía una limitación en sus manitas, por más ejercicios de estimulación que se le hacían no había mayor avance, en cambio el estímulo de poder usar la computadora la ha motivado mucho y ha logrado usarla por sí misma y hacer los movimientos necesarios", "La educación a distancia le ha dado la oportunidad de nuevas posibilidades, hemos descubierto cosas que jamás creímos podría hacer, por ejemplo ya sabe contestar la llamada cuando la llama la maestra".

Por otra parte, el dispositivo tecnológico usado, les ha facilitado el proceso educativo: "No tiene que escribir, por lo que logra hacer los trabajos y enviarlos igual que los demás", "mandan grabaciones de los trabajos que hacen", "en mis clases uso el MS Teams ${ }^{\circledast}$, les pongo videos que luego les comparto, les mando links para clarificar la materia o para que investiguen más", "se usa también el WhatsApp para mandarle alguna cosa, o por correo". Es decir, los estudiantes tienen la posibilidad de acceder al currículo de una forma satisfactoria.

En el caso de las personas estudiantes que usan el dispositivo de control ocular o digital, les ha permitido un mayor acercamiento con su docente, por cuanto se pueden comunicar entre sí, ya sea mediante las clases por MS Teams ${ }^{\circledast}$ o con videollamadas, donde el padre o madre de familia colabora.

Hay docentes que dicen que el "recurso de apoyo tecnológico es un apoyo al proceso educativo a distancia, no lo único" y se valen de otros medios, como lo son el envío de guías de trabajo autónomo GTA: "les mando las GTA cuando los padres vienen por los paquetes de alimentos" y con las normas de accesibilidad que necesite el estudiantado: "en el caso de mi estudiante, a ella le tengo que adecuar el material, ampliarle la letra y en algunos casos, ponerle cierres visuales".

A la vez, algunas personas docentes señalan que mientras que los estudiantes que tienen el dispositivo tecnológico de alta gama, han logrado acceder a las clases y tener múltiples oportunidades, hay un grupo que, al no contar con el recurso, ven limitado su proceso: “La portátil sería un recurso de mucha utilidad para todos los estudiantes, solo pocos la tienen, por lo que ha sido doblemente beneficiado en esta situación de pandemia"

El Programa Estado de la Nación en Educación (2017), indica que se ha convertido en una necesidad ver un aprovechamiento de las herramientas tecnológicas en el entorno escolar y requiere, que los docentes estén actualizados para que puedan ser mediadores oportunos y efectivos, en el uso adecuado de las herramientas modernas.

El aprovechar los recursos con los que se cuenta actualmente, y la iniciativa del estudiantado por querer aprender más y más, donde la persona docente es capaz de atender las inquietudes que presentan, manifiesta una actitud de apertura hacia nuevos enfoques, formas de ver las cosas y nuevas posibilidades, lo cual es básico cuando se tiene en las aulas, estudiantes con alguna situación de discapacidad.

En la modalidad de educación a distancia, la educación virtual es una de las posibilidades, e "incorpora elementos pedagógicos del aprendizaje activo, ya que se constituye en una herramienta interactiva y apropiada tanto para la trasmisión de información como para la construcción del conocimiento por parte de los estudiantes" (Moreno, 2018, p. 18).

De este modo, es que se tiene evidencia que los dispositivos de alta gama que tienen algunos de los estudiantes en condición de discapacidad, han colaborado en forma positiva en el proceso de mediación pedagógica en la modalidad de educación a distancia (ver Figura 2). 


\section{SÍNTESIS Y REFLEXIONES FINALES}

Los productos de apoyo tecnológico de alta gama, cumplen con el propósito de hacer que el sistema educativo sea accesible y equitativo a estudiantes en condición de discapacidad, de las regiones educativas costarricenses de Coto y Liberia, bajo la modalidad de educación a distancia. Cabe señalar, que persiste un concepto de discapacidad desde un modelo rehabilitador, donde se ve a la persona con una carencia o limitación respecto a los demás; otras personas participantes son consistentes en que la discapacidad, es el resultado de relacionarse con un contexto que presenta barreras, que impiden acceder al entorno, ven a la discapacidad desde el modelo social que es lo que actualmente prevalece, de ahí el esfuerzo conjunto de las instituciones del Estado por cumplir con las políticas de accesibilidad, en cumplimientos de los derechos que por naturaleza humana se tienen.

Personas encargadas de familia y personas docentes conocen los conceptos de productos de apoyo a nivel general, y de productos de apoyo educativo que es con el que cuentan, específicamente, el de alta gama, que en la educación a distancia ha sido un gran aliado, por cuanto les ha permitido tener acceso a las clases y las personas docentes lo usan en su mediación pedagógica, siendo un recurso enriquecedor en el proceso de transformación curricular, donde la tecnología es un recurso significativo.

En este sentido, se concluye que el estudiantado y personas docentes usan el dispositivo de apoyo en estrategias de mediación, enriqueciendo las clases, dando oportunidad de poder acceder a mayor conocimiento, facilitando el proceso según las características de la personas estudiantes; no obstante, es un recurso más, no el único y se valen de otras estrategias que complementan los objetivos del currículo.

Así es importante señalar que el CENAREC, específicamente el Daat, cuando la familia o la institución educativa solicita asesoría para el uso de un producto de apoyo, se les brinda; no obstante, la adquisición del recurso como tal, es responsabilidad de otras entidades del Ministerio de Educación. Las personas participantes destacan la necesidad de agilizar el proceso para que logre adquirir el producto de apoyo recomendado, lo cual les asegura tener acceso a un currículo más pertinente y en el cual, se puedan brindar las oportunidades que como personas requieren.

Además, es necesario que docentes y familias del estudiantado cuenten con un acompañamiento y seguimiento para obtener el mayor provecho al producto de apoyo, de forma tal que exista una estrategia en el centro educativo para lograrlo y así, mejorar el rendimiento del que se tiene, lo que asegura una mejor participación de la persona estudiante en situación de discapacidad en el contexto educativo, a la vez, también es pertinente que exista un monitoreo que garantice que el producto se esté usando.

En esta línea, es importante que los planes de estudio de las carreras universitarias relacionadas con Ciencias de la Educación, formen a los futuros profesionales en la educación inclusiva, para que cuenten con los conocimientos generales para brindar acompañamiento a sus estudiantes en condición de discapacidad, así como que existan actividades de formación permanente para el profesorado activo.

A partir de este estudio, se desprenden otras líneas de investigación, como lo puede ser respecto al trámite por el que se giran los recursos para adquirir el producto de apoyo, que determine la necesidad real que hay en la población y los obstáculos que se enfrentan, para no poder hacerlo efectivo en un plazo que responda a los requerimientos y así, reducir los tiempos en el proceso de adquisición. Por otra parte, también se pueden desarrollar las investigaciones relacionadas con las carencias actuales y consecuencias de la educación a distancia en la población estudiantil en general, que no cuenta con acceso a la tecnología y/o a conectividad. Además de experiencias inclusivas específicas en los entornos de aula, con el uso de productos de apoyo y la necesidad de desarrollar procesos de investigación, para que el profesorado desarrolle mayor conocimiento de los recursos tecnológicos disponibles, así como de habilidades digitales para obtener su mejor provecho. 
Aguilar, J.; Córdoba, L.; Chamorro, C.; González, M., Hurtado, N.; Valencia, A. \& Valencia, M. (2009). Equipos multidisciplinares en el diseño de productos de apoyo para personas con discapacidad. Revista Ingeniería Investigación, 29(3), 142-147. Recuperado de http://www.scielo. org.co/img/revistas/iei/v29n3/v29n3a24.pdf

Arnaiz, P. (2003). Educación Inclusiva: Una escuela para todos. Madrid: Ediciones ALJIBE.

Besalú, X. (2002). Diversidad cultural y Educación. Madrid: Síntesis.

Buendía, E.; González, D. y Pozo, T. (2004). Temas fundamentales en la investigación educativa.. España: La Muralla.

Carrascosa, J. (2015). La discapacidad auditiva. Principales modelos y ayudas técnicas para la intervención. Revista Internacional de Apoyo a la Inclusión, Logopedia, Sociedad y Multiculturalidad, 1(1), 24-36.

Echeita, G. (2013). Inclusión y exclusión educativa. “De nuevo voz y quebranto”. Revista Iberoamericana sobre Calidad, Eficacia y Cambio en Educación, 11(2), 99-118. Recuperado de https://www.redalyc. org/pdf/551/55127024005.pdf

González-Hernández, M.; Gudiño-Lau, J.; Guedea-Salazar, J.; Hernández-Barón, E.; Durán-Fonseca, M. \& Vélez-Díaz, D. (2019). Diseño y construcción de un dispositivo mecatrónico para terapia ocupacional para niño. XIKUA Boletín Científico de la Escuela Superior de Tlahuelilpan, 14, 11-18. Recuperado de https://repository.uaeh.edu.mx/revistas/index.php/xikua/issue/archive

Gutiérrez, F. y Prieto, D. (1993). La mediación pedagógica. Apuntes para una educación a distancia. Recuperado de https://campusmoodle.proed.unc.edu.ar/file.php/513/Biblioteca/Mediacion Pedagogica.pdf

Hernández, M. (2015). El Concepto de Discapacidad: De la Enfermedad al Enfoque de Derechos. Revista CES Derecho 6(2), 46-59. Tomado de http://www.scielo.org.co/pdf/cesd/v6n2/v6n2a04.pdf

Hernández, R.; Fernández, C. \& Baptista, P. (2008). Metodología de la Investigación. Cuarta edición. México: Mc Graw Hill Interamericana.

Hernández, R.; Fernandez, C. y Baptista, M. (2014). Metodología de la Investigación. Sexta Edición. Mc Graw Hill Education.

Jiménez, E. (2016). Impacto psicosocial de los productos y tecnologías de apoyo para la comunicación en personas con discapacidad auditiva y personas sordas. Tesis doctoral, Universidad de Salamanca, España. Recuperada de https://sid.usal.es/idocs/F8/FD027380/JimenezArberas.pd

Ministerio de Educación Pública (2013). Circular DVM-AC-003-2013: Lineamientos sobre apoyos curriculares y de acceso para la atención de necesidades educativas del estudiantado en la Educación General Básica y Educación Diversificada.

Ministerio de Educación Pública (2021). Orientaciones de mediación pedagógica para la educación combinada. Recuperado de https://www.mep.go.cr/sites/default/files/page/adjuntos/orientaciones-mediacion-pedagogica-educacion-combinada.pdf

Morales, O. y Cooke, R. (2008). Introducción al modelo clásico de juicio estructurado de expertos: breve recuento del pasado y una aplicación reciente. En Revista Ciencia, ergo sum, Vol. 16-3.

Moreno, A. (2018). Educación y tecnología: estrategias didácticas para la integración de las TIC. Editorial UNED.

Palacios, A. (2008). El modelo social de discapacidad: orígenes, caracterización y plasmación en la Convención Internacional sobre derechos de las personas con discapacidad. Grupo editorial CINCA: Madrid. 
Programa Estado de la Nación en Educación (2017). Sexto Informe Estado de la Educación Costarricense. Recuperado de https://www.estadonacion.or.cr/educacion2017/assets/ee6-informe-completo. pdf

Ríos, D. (2017). La accesibilidad de las TIC en Costa Rica: Un cambio disruptivo en la mente de la sociedad costarricense. Revista Latinoamericana de Derechos Humanos, 28(1), 177-198. Recuperado de https://www.revistas.una.ac.cr/index.php/derechoshumanos/article/view/9660

Rojas, J.; Abello, R.; Garrido, F. y Simanca, F. (2019). EAPP: Plataforma tecnológica para la traducción de voz a texto como apoyo a la educación inclusiva en el proceso de enseñanza en la educación superior (2019). Revista Avenir, 1(1). 23-27. Recuperado de https://fundacionavenir.net/revista/index.php/avenir/article/view/81/29

Schirmer, C. (2020). Investigaciones en recursos de alta tecnología para comunicación y trastorno del espectro autista. Eucação Tematica Digital, 2(1). pp. 68-85. DOI: https://doi.org/10.20396/etd. $\underline{\text { v22i1.8655470 }}$

Tavid, A. (2018). Presentación terapéutica del sistema Tobbi en Centro A. La Par. Recuperado de https:// www.youtube.com/watch?v=fujOBFfnQLU

Taylor, S. y Bogdan, R. (2006). Introducción a los métodos cualitativos de investigación. Barcelona. Editorial: Paidós.

Victoria, J. (2013). El modelo social de la discapacidad: una cuestión de derechos humanos. Boletín mexicano de derecho comparado. N. 46 (138). Tomado de http://www.scielo.org.mx/scielo. php?script=sci_arttext $\&$ pid=S0041-86332013000300008

Víquez-Alfaro, C.; López-Garbanzo, L.; Cordero-Salas, M. y Alpízar-Alfaro, P. (2019). Fortalecimiento de la autonomía de jóvenes con discapacidad intelectual mediante la aplicación de las TIC. Innovaciones Educativas, 21(30), 48-61. Recuperado de https://doi.org/10.22458/ie.v21i30.2484 